\title{
A Gas Turbine Diagnostic Approach with Transient Measurements
}

\author{
Y. G. Li \\ Department of Propulsion, Power and Aerospace Engineering, School of Engineering, \\ Cranfield University, Bedford MK43 OAL, England
}

\begin{abstract}
Most gas turbine performance analysis based diagnostic methods use the information from steady state measurements. Unfortunately, steady state measurement may not be obtained easily in some situations and some types of gas turbine faults contribute little to performance deviation at steady state operation conditions but significant during transient processes. Therefore, gas turbine diagnostics with transient measurement is superior to that with steady state measurement.

In this paper, an accumulated deviation is defined for gas turbine performance parameters in order to measure the level of performance deviation during transient processes. The features of the accumulated deviation are analyzed and compared with traditionally defined performance deviation at a steady state condition. A non-linear model based diagnostic method, combined with genetic algorithm (GA), is developed and applied to a model gas turbine engine to diagnose engine faults by using the accumulated deviation obtained from transient measurement. Typical transient measurable parameters of gas turbine engines are used for fault diagnostic purpose and a typical slam acceleration process from idle to maximum power is chosen in the analysis. The developed diagnostic approach is applied to the model engine implanted with three typical single component faults and is proved to be very successful.
\end{abstract}


KEYWORDS: gas turbine, engine, diagnostics, transient, performance, fault detection, genetic algorithm

\section{NOMENCLATURE}

C friction coefficient

$f() \quad$ function

$F() \quad$ function

$f \quad$ friction $(N)$

$m_{f} \quad$ fuel flow rate $(\mathrm{kg} / \mathrm{s})$

$N \quad$ relative shaft speed (\%); number of measurable parameters

$P \quad$ total pressure $(k P a)$

$r \quad$ shaft radium $(m)$

$T \quad$ total temperature $(K)$

$t \quad$ time $(s)$

$W \quad$ power $(W)$

$\vec{x} \quad$ component parameter vector

$z_{i} \quad$ measurable parameter

$\vec{z} \quad$ measurable parameter vector

$\eta \quad$ efficiency

$\pi \quad 3.14159$

$\bar{\sigma}_{i} \quad$ average standard deviation of $i$-th measurement

$\Delta \quad$ small change

$\Gamma \quad$ flow capacity 


\section{$\underline{\text { Superscripts }}$}

$\wedge \quad$ estimated
$\sim \quad$ accumulated deviation

\section{$\underline{\text { Subscripts }}$}

$\begin{array}{ll}b & \text { burner } \\ f & \text { fuel } \\ \max & \text { maximum } \\ n & \text { nominal or clean } \\ r e f & \text { reference } \\ t & \text { total } \\ 0 & \text { starting point } \\ 2 & \text { HP compressor exit } \\ 5 & \text { LP turbine exit } \\ 15 & \text { HP compressor inlet }\end{array}$

\section{NOTATIONS}

FC fault class

GA genetic algorithm

HP high pressure

HPC high pressure compressor

$H P B \quad$ high pressure shaft bearings

HPT high pressure turbine 
IP intermediate pressure

IPC intermediate pressure compressor

LP low pressure

LPC low pressure compressor

$L P B \quad$ low pressure shaft bearings

LPT low pressure turbine

\section{INTRODUCTION}

The performance of gas turbine engines deteriorate during their operation due to component degradation. Therefore, necessary maintenance is required to keep the engine condition at high level. Traditionally, engine maintenance is carried out following manufacturer's schedule. In order to shift from pre-scheduled maintenance to condition monitored maintenance, gas turbine condition monitoring and diagnostics must be used.

Most gas turbine diagnostics uses the information from engine steady state measurements. Unfortunately, in some situations good quality steady state measurements are difficult to obtain, such as those of military aircraft engines that operate up to $70 \%$ of the total mission time at unsteady conditions, Merrington [16]. In addition, some gas turbine component faults, such as bearing fault [15] and mis-scheduled final nozzle control during transients [17], contribute little to steady state performance deviation but significant to transient performance change. Furthermore, performance shift due to engine faults is very likely to be magnified during transients compared to that at corresponding steady state conditions. Therefore, gas turbine fault detection with transient measurements is beneficial in these cases. Gas turbine engine performance deterioration and 
fault signatures during transient processes and fault diagnosis were analyzed by Merrington et al. [16-19], Henry [8], Luppold et al. [12], Kerr et al. [9], Bird and Schwartz [1], and Lunderstaedt and Junk [11].

Different gas turbine performance analysis based diagnostic techniques have been developed since Urban [23] introduced the first gas path analysis method in 1967 and a comprehensive review of these techniques was provided by Li [10]. Different methods of simulating engine performance degradation have been developed by many researchers, such as Saravanamuttoo and Maclsaac [22]. Non-linear model based diagnostic approach using genetic algorithm (GA) as an optimization tool is one of the powerful methods to diagnose gas turbine faults. It has been used since 1999 by many researchers, such as Zedda and Singh [2526], Gulati et al. [6-7], Gröntedt [5] and Sampath et al. [21], and have been proved to be successful.

In this paper, the non-linear model-based diagnostic approach is extended to gas turbine fault diagnosis with engine transient measurements. The transient performance change due to engine faults is measured with an engine performance accumulated deviation defined in this paper. The features of the accumulated deviation are analyzed and compared with steady state performance deviation. A model gas turbine engine whose transient performance is simulated with a transient performance code is used for the diagnostic analysis. The developed diagnostic approach is applied to the model engine implanted with three different single component faults. The effectiveness of the new diagnostic approach is shown and analyzed.

\section{MODEL ENGINE}

Due to the unavailability of real engine data, a model gas turbine engine (Figure 1) is chosen for the diagnostic analysis. It is a two spool turbofan engine where the basic performance parameters are shown as follows:

$\begin{array}{ll}\text { Total mass flow rate } & 200 \mathrm{~kg} / \mathrm{s} \\ \text { Total pressure ratio } & 19\end{array}$


Bypass ratio

Turbine entry temperature

A slam acceleration process from idle to maximum thrust is chosen for the analysis because it is one of the most frequently used transient processes for gas turbine engines. It is also a process where the starting point is easy to set for both engine transient measurements and engine transient performance modeling required by the diagnostic approach.

A fuel control schedule expressed in a non-dimensional form, Equation (1), is applied to the engine. Therefore, the actual fuel flow rate is determined by the pressure ratio of HP compressor, HP shaft speed and HP compressor discharge total pressure.

$$
\left\{\begin{array}{cll}
m_{f} / N_{H P} P_{t 2}=f\left(P_{t 2} / P_{t 15}\right), & \text { if } & m_{f}<m_{f, \text { max }} \\
m_{f}=m_{f, \text { max }}, & \text { if } & m_{f} \geq m_{f, \text { max }}
\end{array}\right.
$$

A transient performance prediction code developed by Maccallum [14] for the model gas turbine engine is modified for the analysis. The prediction of the transient performance is established based on the continuity of mass and energy. Inter-Component Volume method [4] is used to take into account the effect of air (or gas) accumulation or diminution within engine components and ducts. The effect of heat transfer between air (or gas) and engine component is also included in the simulation. The engine performance model behaves highly non-linear and can be used to simulate the engine behaviour in a variety of operation conditions. The original code was used to predict the transient processes of Rolls-Royce Spey and Tay engines and satisfactory results were obtained [13]. Details of the transient prediction methods were described by Maccallum and Qi [14] and Pilidis [20].

Engine models can be tuned to simulate real engine performance accurately. Due to the fact that current research is to develop a diagnostic approach with transient measurement, it is assumed that the engine model 
is accurate enough to simulate real engine bahaviour during transient processes. Tuning techniques are beyond the scope of this paper and therefore not discussed.

The degradation of compressors and turbines is represented with the drop of isentropic efficiencies and the change in flow capacities. Combustor degradation is represented with the drop of combustion efficiency. Shaft bearing failure is simulated and implanted by extracting certain amount of power done by increased bearing friction from either HP or LP shaft. The power is calculated with Equations (2) to (3). To simplify the analysis, it is assumed that the friction is constant during a transient process for certain level of bearing failure.

$$
\begin{aligned}
& W_{H P B}=\left(C_{H P B}-1\right) \cdot\left(f_{H P B} \cdot r_{L P}\right) \cdot\left[2 \pi\left(N_{H P}-N_{L P}\right)\right] \\
& W_{L P B}=\left(C_{L P B}-1\right) \cdot\left(f_{L P B} \cdot r_{L P}\right) \cdot\left(2 \pi N_{L P}\right)
\end{aligned}
$$

When HP shaft bearings fail, the power consumed due to increased friction is extracted from HP shaft and applied to LP shaft. When LP shaft bearings fail, the power consumed is only extracted from LP shaft. Due to lack of experimental data, it is assumed that the increase of bearing friction results in the extra power consumption in the order of up to $0.4 \%$ (corresponding to $C_{H P B}=1.04$ ) of HP turbine power when the engine operates at its maximum power. The variation of the ratio of the HP shaft extra power consumption and the HP turbine power during the acceleration is shown in Figure 2 while the variation of the HP shaft extra power consumption relative to the HP turbine power at engine maximum power condition is shown in Figure 3 for different $C_{H P B}$ varying from 1.01 to 1.04 . It can be seen that although the bearing loss does not change too much when the engine accelerates from low to high operating conditions the percentage of this extra power consumption relative to the HP turbine power is up to twenty times larger when the engine operates at low operating conditions than at high operation conditions. Therefore, the impact of bearing failure is larger when the engine operates at low operating conditions than at high operating conditions. 


\section{PERFORMANCE DEVIATION}

Traditionally, the deviation of gas turbine performance parameters is defined as the shift of the parameters from their nominal values at a steady state condition due to performance degradation, and is expressed as follows:

$$
\Delta z=\frac{z-z_{n}}{z_{n}}
$$

where $z$ is the current value of a performance parameter and $z_{n}$ the nominal value of the parameter. Such a definition is based on the assumption that the measurements are made on the same steady state operation point. When an engine is new, there should have no deviations to all the measurable parameters. When the engine is degraded, the deviations of the measurable parameters are used by a diagnostic system for fault detection, isolation and quantification. Unfortunately, such a deviation concept can not be easily applied to transient process diagnostics.

In order to diagnose gas turbine faults by analyzing transient measurements, the analysis of performance deviation for the whole transient process is more useful than at certain operation point. Therefore, a new definition of an accumulated deviation is introduced to measure the shift of a parameter trajectory from its nominal position (Figure 4) due to engine component degradation and is defined as the area between the two trajectories divided by the area under the nominal trajectory during the transient period and is expressed in Equation (5), or in a discrete form in Equation (6).

$$
\Delta \widetilde{z}=\frac{\int_{t_{0}}^{t}\left[z(t)-z_{n}(t)\right] d t}{\int_{t_{0}}^{t} z_{n}(t) d t}
$$




$$
\Delta \widetilde{z}=\frac{\sum_{i=I_{t_{0}}}^{I_{t}}\left[z\left(t_{i}\right)-z_{n}\left(t_{i}\right)\right]}{\sum_{i=I_{t_{0}}}^{I_{t}} z_{n}\left(t_{i}\right)}
$$

The sampling time step is 0.2 second for Equation (6), which is a typical value for transient measurement; smaller sampling time step would be beneficial in reducing the impact of measurement noise. In real applications, measurement noise would be added to the $z(t)$ and $z_{n}(t)$ signals but the accumulated deviation $\Delta \widetilde{z}$ would be noise free if the sampling time step is small enough.

By comparing the behavior of the steady state deviation and the accumulated deviation of the model engine during the slam acceleration, it is found that:

(1) The deviation at steady state is a special case of the accumulated deviation where the accumulated deviation is calculated at a specific moment. In addition, when the engine operates on its steady state conditions, two deviations have the same value.

(2) The difference between the steady state deviation and the accumulated deviation becomes smaller for a specific transient process when the integration time in Equation (5) becomes longer. Figure 5 shows how the accumulated deviation of the LP shaft speed of the model engine varies with the integration time $t$ in Equation (5) when a HP turbine fault is implanted (efficiency drop of $2 \%$ and flow capacity rise of $4 \%$ ) into the model engine. It also shows that nearly at the end of the acceleration $(t \approx 8 s)$, Figure 6 , the accumulated deviation reaches its maximum absolute value, which indicates how we can take the most advantage of this approach.

(3) A fault signature expressed with the accumulated deviations is very likely to be magnified compared to the fault signature expressed with the steady state deviations for the same component faults. This phenomenon is well illustrated in Figures 7 to 8 when two different single component faults are implanted 
into the model engine. This feature would benefit fault diagnosis when the accumulated deviations are used.

(4) The two deviations for the same parameters may show different variations, i.e. they may not have the same sign. Examples of it are the fault signature of a HP shaft bearing fault shown in Figure 8 where the bearing friction coefficient of $C_{H P B}=1.04$ is implanted and the fault signature of a LP turbine fault shown in Figure 9 where 2\% efficiency drop and 4\% flow capacity drop are implanted.

Gas turbine component degradation affects both steady and transient performance and this effect is also magnified by engine control schedule. For this specific engine, for example, it can be seen that when engine performance is degraded the fuel flow rate also deviates from its nominal schedule due to the fact that the non-dimensional fuel flow rate is determined by HP compressor pressure ratio determined by Equation (1), which in turn magnifies the performance deviation during transients. Therefore, the impact on transient performance is very likely to be larger than on steady state performance. This phenomenon is well illustrated in Figures 6, and 10 to 16 by comparing the performance with and without degradation during the acceleration of the model turbofan engine implanted with a HP turbine fault simulated with $2 \%$ thermal efficiency drop and 4\% flow capacity rise and a HP shaft bearing failure simulated with an extra HP shaft power consumption defined by Equation (2) when $C_{H P B}=1.04$ equivalent to $0.4 \% \mathrm{HP}$ turbine power at engine maximum power condition. It can be seen that the difference between the nominal and the degraded engine is very small at idle before the acceleration. Then the acceleration process is obviously delayed for the degraded engine due to degraded components and the impact from the control schedule. When the engine reaches its steady state condition after the acceleration the difference between the nominal and degraded engine become small again. In addition, there is no difference in fuel flow rate for the nominal and degraded engine after the acceleration because the fuel flow rate reaches its maximum value controlled by the control schedule. 
Correspondingly, the fault signatures expressed with the accumulated deviation (Equation 5) are much larger than the fault signatures expressed with the traditionally defined steady state deviation (Equation 4). For example, many accumulated deviations due to LP or HP turbine fault are about doubled or tripled compared to those of steady state deviations (Figures 7 and 9), while for HP bearing fault the difference is even more significant (Figure 8). The deviation of the fuel flow rate behaves differently compared to those of other measurable parameters (Figures 7 to 9), where the steady state deviation of the fuel flow rate is zero while the corresponding accumulated deviation is significant. Therefore, diagnostic systems using transient measurements have greater potential to accurately detect the faults than diagnostic systems using steady state measurements especially when measurement noises exist.

\section{NON-LINEAR MODEL-BASED METHOD}

The diagnostic method used in this paper is a non-linear model-based approach and the idea of the model is illustrated in Figure 17. It is assumed that the engine model is able to simulate the performance of the real engine accurately. The real engine component parameter vector $\vec{x}$ determines the engine measurable parameter vector $\vec{z}$. With an initial guessed parameter vector $\hat{\bar{x}}$, the engine model

$$
\vec{z}(t)=F\left[\vec{x}(t), m_{f}(t)\right]
$$

where 


$$
\vec{z}=\left(\begin{array}{c}
N_{H P} \\
N_{L P} \\
m_{f} \\
P_{t 2} \\
T_{t 2} \\
P_{t 5} \\
T_{t 5}
\end{array}\right) \quad \text { and }=\left(\begin{array}{c}
\eta_{I P C} \\
\Gamma_{I P C} \\
\eta_{H P C} \\
\Gamma_{H P C} \\
\eta_{b} \\
\eta_{H P T} \\
\Gamma_{H P T} \\
\eta_{L P T} \\
\Gamma_{L P T} \\
C_{H P B} \\
C_{L P B}
\end{array}\right)
$$

also described in Tables 1 and 2, produces a predicted measurable parameter vector $\hat{\bar{z}}$. An optimization process is applied to minimize an objective function defined in Equation (9) or (10) whose idea is borrowed from the references [25-26] with the difference that the objective function defined by Equation (9) or (10) uses the integral of the measurable parameters in the period of the acceleration while the objective function in [25-26] uses the values of the measurable parameters at steady state conditions.

$$
\begin{aligned}
& \text { Objective Function }=\sum_{i=1}^{N} \frac{\left|\int_{t_{0}}^{t}\left(\hat{z}_{i}(t)-z_{i}(t)\right) d t\right|}{\left|\int_{t_{0}}^{t} z_{i} d t\right| \cdot \bar{\sigma}_{i}} \\
& \text { Objective Function }= \\
& \sum_{i=1}^{N} \frac{\left|\sum_{j=J_{t_{0}}}^{J_{t}}\left[\hat{z}_{i j}\left(t_{j}\right)-z_{i j}\left(t_{j}\right)\right]\right|}{\left|\sum_{j} z_{i j}(t)\right| \cdot \bar{\sigma}_{i}}
\end{aligned}
$$

The standard deviation $\bar{\sigma}_{i}$ accounts for the measurement uncertainty and are calculated based on the assumption of Gaussian distribution for measurement noises and the noise level given by Dyson and Doel [2]. 
It is also assumed that the same transient process is used to obtain both the predicted and measured engine measurable parameters. The searching of the minimum of the objective function is an iterative procedure. When a best estimation of engine component parameter vector $\hat{\bar{x}}$ is found, the objective function reaches its minimum.

\section{GENETIC ALGORITHM}

There are different conventional optimization methods available for the minimization required in the nonlinear model-based diagnostic approach. Unfortunately, they may get stuck at a local minimum because of the nature of the approaches. In this paper, a genetic algorithm (GA) is used in the minimization process.

Genetic algorithm is a searching and optimization technique. Compared with conventional optimization methods, GA has several distinctive features: no derivatives are needed so any non-smooth function can be optimized; constraints can be dealt with in a very different way, such as by means of penalty functions or design of specific operations; global search is used to avoid getting stuck in a local minimum; and probabilistic rather than deterministic transition rules are used to create the next generation of strings from the current one. Three operations are typically used in Genetic Algorithm; they are selection operation which chooses the strings for the next generation according to a "survival of the fittest" criteria, crossover operation which allows information exchange between strings in the form of swapping of parts of the parameter vector in an attempt to get better strings, and mutation operation which introduces new or prematurely lost information in the form of random changes applied to randomly chosen vector components.

A genetic algorithm (GA)/evolution strategy function optimization package, GENIAL 1.1, developed by

Widell [24] is used to minimize the objective function. It uses a real-number encoding and is written in FORTRAN 77. Three major modules are used by GENIAL and the setting of the modules is given in Table 3. It is freely available at website and provides convenient interface for different applications. 


\section{FAULT DIAGNOSIS AND ANALYSIS}

In order to diagnose the faults of the model engine by using transient measurements during the acceleration process, typical engine measurable parameters are chosen and they are listed in Table 1.

In transient measurement, the time constants of sensors especially thermal couples will cause delay in the measurement and therefore have influence on the measurement accuracy, which must be taken into account in real applications with proper calibration and correction. In this study, the effect of time constants is ignored for simplicity.

Sensor noise is found to be insensible to the accumulated deviations because the influence of measurement noise becomes very small when the accumulated deviation is calculated with integration, Equation (3) or (4). Therefore, sensor noise is not considered in this study. In addition, all the sensors are assumed to be fault free for simplicity although the diagnostic approach has the capability to tackle sensor faults.

To simplify the analysis, it is assumed that only single engine components may be faulty and seven major engine single component faults are taken into account. Simulated transient measurements of the engine implanted with three engine component faults are used to test the effectiveness of the diagnostic approach. The three implanted fault cases and the component parameters used to described the faults are listed in Table 2.

Direct search for a gas turbine fault within an eleven-dimensional space corresponding to 11 potentially degraded component (independent) parameters with 7 measurements (dependent parameters) is inaccurate because the number of independent parameters is less than the number of dependent parameters, and is very time consuming even if a solution can be obtained. Based on the fact that a single engine component fault is the most common case in fault diagnosis of gas turbine engines, seven fault classes shown in Table 2 with 
corresponding parameters to describe the faults are considered where each single component fault is regarded as one fault class. Therefore, seven separate searches are carried out to isolate a component fault, where it is assumed that in each search only one class of fault may happen. By comparing the seven objective functions obtained in the seven searches the lowest objective function amongst all the fault classes indicates the most possible fault. This approach the advantages that searched result for any of the fault classes in one or two dimensional space (corresponding to one or two component parameters describing one fault class) is unique due to highly redundant (7) measurements and the computation time is much shorter than direct search in 11dimensional space. This method was introduced by Zedda and Singh [25-26].

In this paper, three engine fault cases are studied and the search results are shown in Table 4. It is obvious that for each of the faults the diagnostic system search all possible fault classes and it only obtains the minimum objective function when the correct fault class is searched. Furthermore, the faulty component is easy to pick up correctly because the objective function corresponding to the faulty component is much smaller than others. It is proved that the approach is able to identify any of these component faults effectively without misleading. This is due to the fact that the fault signatures expressed with accumulated deviations are magnified during the acceleration compared with the fault signatures expressed with steady state deviations. Consequently, the fault signatures of the three engine faults are significant enough for the diagnostic approach to identify and quantify the faults accurately.

Search for some fault classes, such as FC1 (IP compressor fault), FC2 (HP compressor fault), FC4 (HP turbine fault) and FC5 (LP turbine fault), is within two-dimensional space and other fault classes, such as FC3 (combustor fault), FC6 (HP shaft bearing fault) and FC7 (LP shaft bearing fault) is within one-dimensional space. The computation time for each search takes about 1 hour on a personal computer (Pentium III). 


\section{CONCLUSIONS}

The introduction of transient accumulated deviation has been proved to be a useful new concept to measure performance deviation of gas turbine engines during transient processes. The comparison of fault signatures expressed with the accumulated deviation and the steady state deviation shows that gas turbine component fault diagnosis using transient data can be more effective than using steady state data due to magnified fault signatures. Diagnostics with transient measurements becomes more useful than with steady state measurements when steady state measurements are difficult to obtain and when engine faults contribute little to performance deviation at steady state conditions but significant at transient processes. A non-linear modelbased diagnostic approach using typical gas turbine transient measurements, combined with a genetic algorithm, has been proved to be very successful by applying the approach to a model gas turbine turbofan engine implanted with some typical single component faults.

\section{AKNOWLEDGEMENTS}

The present research is supported by a Platform Grant of the Engineering and Physical Sciences Research Council (EPSRC), United Kingdom.

\section{REFERENCES}

1. Bird J. W. and Schwartz H. M., "Diagnosis of Turbine Engine Transient Performance with Model-Based Parameter Estimation Techniques", ASME 94-GT-317, 1994.

2. Dyson R. J. E. and Doel D. L., "CF6-80 Condition Monitoring - The Engine Manufacturer's Involvement in Data Acquisition and Analysis", AIAA-84-1412, 1984. 
3. Eustace R. W., Woodyatt B. A., Merrington G. L. and Runacres A., "Fault Signatures Obtained from Fault Implant Tests on an F404 Engine", Journal of Engineering for Gas Turbines and Power, Vol.116, pp.178-183, January 1994.

4. Fawke A.J. and Saravanamuttoo H.I.H., "Digital Computer Methods for Prediction of Gas Turbine Dynamic Response", SAE Paper 710550, 1971.

5. Grönstedt T. U. J., “A Multi-Point Gas Path Analysis Tool for Gas Turbine Engines with a Moderate Level of Instrumentation", ISABE-2001-1051, 15 ${ }^{\text {th }}$ ISABE, Bangalore, India, Sept. 2001.

6. Gulati A., Taylor D. and Singh R., "Multiple Operating Point Analysis Using Genetic Algorithm Optimisation for Gas Turbine Diagnostics", ISABE-2001-1139, $15^{\text {th }}$ ISABE, Bangalore, India, Sept. 2001.

7. Gulati A., Zedda M. and Singh R., "Gas Turbine Engine and Sensor Multiple Operating Point Analysis Using Optimization Techniques", AIAA-2000-3716, 2000.

8. Henry J. R., "CF-18/F404 Transient Performance Trending", AGARD-CP-448, Engine Condition Monitoring - Technology and Experience, Oct. 1988.

9. Kerr L. J., Nemec T. S. and Gallops G. W., "Real-Time Estimation of Gas Turbine Engine Damage Using a Control-Based Kalman Filter Algorithm", Journal of Engineering for Gas Turbines and Power, Vol.114, pp.187-195, April 1992.

10. Li G.Y., "Performance Analysis Based Gas Turbine Fault Diagnostics: A Review", to be published by IMechE Proceedings, Part A: Journal of Power and Energy.

11. Lunderstaedt R. A. and Junk R. H., "Application of the Gas - Path Analysis (GPA) for the NonStationary Operation of a Jet Engine", ISABE-97-7062, $13^{\text {th }}$ ISABE, Chattanooga, Tennessee, USA, Sept. 1997. 
12. Luppold R. H., Roman J. R., Gallops G. W. and Kerr L. J., "Estimating In-Flight Engine Performance Variations Using Kalman Filter Concepts", AIAA-89-2584, 1989.

13. Maccallum N.R.L., "Computational Models for the Transient Performance of RB183-02 (Spey) and RB183-03 (Tay) Engines", TR RR/1, Dept. of Mechanical Engineering, University of Glasgow, Glasgow, Scotland, UK, Aug. 1984.

14. Maccallum N.R.L. and Qi O.F., "The Transient Behavior of Aircraft Gas Turbines", IMechE Seminar (Seminar S777) on "Gas Turbines: Technology and Developments", Inst. Of Mechanical Engineering, London, Nov. 1989.

15. Meher-Homji C.B. and Bhargava R., "Condition Monitoring and Diagnostic Aspects of Gas Turbine Transient Response”, ASME Paper 92-GT-100, 1992.

16. Merrington G. L., "Fault Diagnosis of Gas Turbine Engines From Transient Data", Journal of Engineering for Gas Turbines and Power, Vol.111, pp.237-243, April 1989.

17. Merrington G. L., "Identification of Dynamic Characteristics for Fault Isolation Purpose in a Gas Turbine Using Closed-Loop Measurements", AGARD-CP-448, Engine Condition Monitoring Technology and Experience, Oct. 1988.

18. Merrington G., Kwon O.-K., Goodwin G. and Carlsson B., "Fault Detection and Diagnosis in Gas Turbines", Journal of Engineering for Gas Turbines and Power, Vol.113, pp.276-282, April 1991.

19. Merrington G.L., "Fault Diagnosis in Gas Turbines Using a Model-Based Technique", Journal of Engineering for Gas Turbine and Power, Vol.116, pp.374-380, April 1994.

20. Pilidis P., "Digital Simulation of Gas Turbine Performance", PhD Dissertation, Dept. of Mechanical Engineering, University of Glasgow, Scotland, UK, Nov. 1983.

21. Sampath S., Gulati A. and Singh R., "Fault Diagnostics Using Genetic Algorithm for Advanced Cycle Gas Turbine”, ASME GT-2002-30021, June 2002. 
22. Saravanamuttoo H.I.H. and Maclsaac B.D., "Thermodynamic Models for Pipeline Gas Turbine Diagnostics", Journal of Engineering for Power, Vol.105, pp.875-884, October 1983.

23. Urban L. A., "Gas Turbine Engine Parameter Interrelationship", HSD UTC, Windsor Locks, Ct., $1^{\text {st }}$ edition, $1967,2^{\text {nd }}$ edition, 1969.

24. Widell H., "GENIAL 1.1: A Friendly Function Optimizer Based on Evolutional Algorithms - User Manual", http://hjem.get2net.dk/widell/genial.htm, July 1998.

25. Zedda M. and Singh R., "Gas Turbine Engine and Sensor Fault Diagnosis Using Optimisation Techniques", AIAA-99-2530, 1999.

26. Zedda M. and Singh R., "Gas Turbine Engine and Sensor Diagnostics", ISABE 99-7238, 13" ISABE, 1999. 
Table 1. Engine measurement set $(\vec{z})$

\begin{tabular}{|l|c|l|}
\hline Parameter & Unit & Meanings \\
\hline$N_{H P}$ & $\%$ & Relative HP shaft speed \\
\hline$N_{L P}$ & $\%$ & Relative LP shaft speed \\
\hline$m_{f}$ & $\mathrm{~kg} / \mathrm{s}$ & Fuel flow rate \\
\hline$P_{t 2}$ & $\mathrm{kPa}$ & HP compressor exit total pressure \\
\hline$T_{t 2}$ & $\mathrm{~K}$ & HP compressor exit total temperature \\
\hline$P_{t 5}$ & $\mathrm{kPa}$ & LP turbine exit pressure \\
\hline$T_{t 5}$ & $\mathrm{~K}$ & LP turbine exit temperature \\
\hline
\end{tabular}


Table 2. Fault classes and implanted engine single component fault cases

\begin{tabular}{|c|c|c|c|c|c|}
\hline Fault & Faulty Component & \multicolumn{2}{|c|}{ Component Parameters $(\vec{x})$} & \multicolumn{2}{|c|}{ Implanted Faults } \\
\hline \multirow[t]{2}{*}{$\mathrm{FCl}$} & \multirow[t]{2}{*}{ IP compressor } & $\eta_{I P C}$ & Thermal efficiency & & \\
\hline & & $\overline{\Gamma_{I P C}}$ & Flow capacity & & \\
\hline \multirow[t]{2}{*}{$\mathrm{FC2}$} & \multirow[t]{2}{*}{ HP compressor } & $\eta_{H P C}$ & Thermal efficiency & $-2 \%$ & \multirow{2}{*}{ Case 1} \\
\hline & & $\overline{\Gamma_{H P C}}$ & Flow capacity & $-4 \%$ & \\
\hline FC3 & Combustor & $\eta_{b}$ & Combustion efficiency & & \\
\hline \multirow[t]{2}{*}{$\overline{\mathrm{FC} 4}$} & \multirow[t]{2}{*}{ HP turbine } & $\eta_{H P T}$ & Thermal efficiency & $-2 \%$ & \multirow{2}{*}{ Case 2} \\
\hline & & $\overline{\Gamma_{H P T}}$ & Flow capacity & $+4 \%$ & \\
\hline \multirow[t]{2}{*}{ FC5 } & \multirow[t]{2}{*}{ LP turbine } & $\eta_{L P T}$ & Thermal efficiency & & \\
\hline & & $\overline{\Gamma_{L P T}}$ & Flow capacity & & \\
\hline FC6 & HP shaft bearings & $\overline{C_{H P B}}$ & Friction coefficient & 1.04 & Case 3 \\
\hline$\overline{\text { FC7 }}$ & LP shaft bearings & $\overline{C_{L P B}}$ & Friction coefficient & & \\
\hline
\end{tabular}


Table 3. Module setting of DENIAL program

\begin{tabular}{|l|l|}
\hline \multicolumn{2}{|c|}{ Evolution Module } \\
\hline Function & User Function (engine model) \\
\hline Worst fitness & 1. E20 \\
\hline Problem type & Minimization \\
\hline Number of variables & 1 or 2 \\
\hline Number of evolutions & 300 \\
\hline \multicolumn{2}{|c|}{ Population Module } \\
\hline Population size & 90 \\
\hline Reproduction model & Steady state without duplicates \\
\hline Parent selection method & Stochastic tournament \\
\hline Replacement method & Exponential ranking \\
\hline \multicolumn{2}{|c|}{ Reproduction Module } \\
\hline Number of operators & 2 \\
\hline Uniform arithmetical crossover & $35.0, \quad 1.0, \quad 0.5$ \\
\hline Uniform creep & $5.0, \quad 0.7, \quad 0.001$ \\
\hline
\end{tabular}


Table 4. Searching for the implanted single component faults

\begin{tabular}{|c|c|c|c|c|c|c|c|c|c|}
\hline \multirow{3}{*}{$\begin{array}{l}\text { Fault } \\
\text { class }\end{array}$} & \multirow{3}{*}{\multicolumn{2}{|c|}{$\begin{array}{l}\text { Component } \\
\text { parameters \& } \\
\text { implanted } \\
\text { faults }\end{array}$}} & \multirow{3}{*}{$\begin{array}{l}\text { Search } \\
\text { range }\end{array}$} & \multicolumn{6}{|c|}{ Search results for three fault cases } \\
\hline & & & & \multicolumn{2}{|c|}{ Case 1} & \multicolumn{2}{|c|}{ Case 2} & \multicolumn{2}{|c|}{ Case 3} \\
\hline & & & & $\begin{array}{c}\text { Predicted } \\
\text { component } \\
\text { deviation }\end{array}$ & $\begin{array}{l}\text { Objective } \\
\text { Function }\end{array}$ & $\begin{array}{c}\text { Predicted } \\
\text { component } \\
\text { deviation }\end{array}$ & $\begin{array}{l}\text { Objective } \\
\text { Function }\end{array}$ & $\begin{array}{c}\text { Predicted } \\
\text { component } \\
\text { deviation }\end{array}$ & $\begin{array}{l}\text { Objective } \\
\text { Function }\end{array}$ \\
\hline \multirow[t]{2}{*}{$\mathrm{FC1}$} & $\eta_{I P C}$ & & $-5 \% \sim 0 \%$ & & \multirow{2}{*}{2.174} & & \multirow{2}{*}{75.08} & & \multirow[b]{2}{*}{56.68} \\
\hline & $\Gamma_{I P C}$ & & $-5 \% \sim 0 \%$ & & & & & & \\
\hline \multirow[t]{2}{*}{$\mathrm{FC} 2$} & $\eta_{H P C}$ & $-2 \%$ & $-5 \% \sim 0 \%$ & $-1.94 \%$ & \multirow[t]{2}{*}{0.242} & & \multirow{2}{*}{15.27} & & \multirow{2}{*}{7.107} \\
\hline & $\Gamma_{H P C}$ & $-4 \%$ & $-5 \% \sim 0 \%$ & $-3.86 \%$ & & & & & \\
\hline FC3 & $\eta_{b}$ & & $-5 \% \sim 0 \%$ & & 68.1 & & 47.91 & & 67.10 \\
\hline \multirow[t]{2}{*}{$\mathrm{FC4}$} & $\eta_{H P T}$ & $-2 \%$ & $-5 \% \sim 0 \%$ & & \multirow[b]{2}{*}{5.016} & $-2.07 \%$ & \multirow{2}{*}{0.164} & & \multirow[b]{2}{*}{5.309} \\
\hline & $\Gamma_{H P T}$ & $+4 \%$ & $-5 \% \sim+5 \%$ & & & $+3.88 \%$ & & & \\
\hline \multirow[t]{2}{*}{$\overline{\mathrm{FC} 5}$} & $\eta_{L P T}$ & & $-5 \% \sim 0 \%$ & & \multirow[b]{2}{*}{2.331} & & \multirow[b]{2}{*}{31.19} & & \multirow[b]{2}{*}{21.10} \\
\hline & $\Gamma_{L P T}$ & & $-5 \% \sim+5 \%$ & & & & & & \\
\hline FC6 & $C_{H P B}$ & 1.04 & $0 \sim 1.08$ & & 6.010 & & 10.13 & 1.04 & 0.0425 \\
\hline FC7 & $C_{L P B}$ & & $0 \sim 1.20$ & & 4.673 & & 58.27 & & 37.46 \\
\hline
\end{tabular}




\section{List of captions:}

Figure 1. Model gas turbine turbofan engine

Figure 2. Variation of the ratio of HP shaft bearing loss and HP turbine power

Figure 3. Variation of HP shaft bearing loss

Figure 4. Trajectories of a nominal and degraded performance parameter

Figure 5. Accumulated deviation changes with differencet integration time

Figure 6. Fuel flow rate change due to HP turbine fault

Figure 7. Fault signatures of a HP turbine fault ( $2 \%$ efficiency drop and $4 \%$ flow capacity rise)

Figure 8. Fault signatures of HP shaft bearing failure $\left(C_{H P B}=1.04\right)$

Figure 9. Fault signature of LP turbine fault (2\% efficiency drop and $4 \%$ flow capacity drop)

Figure 10. Shaft speed changes due to HP turbine fault

Figure 11. Total pressure changes due to HP turbine fault

Figure 12. Total temperature changes due to HP turbine fault

Figure 13. Fuel flow rate change due to HP shaft bearing failure

Figure 14. Shaft speed changes due to HP shaft bearing failure

Figure 15. Total pressure changes due to HP shaft bearing failure

Figure 16. Total temperature changes due to HP shaft bearing failure

Figure 17. Non-linear model-based diagnostic model 


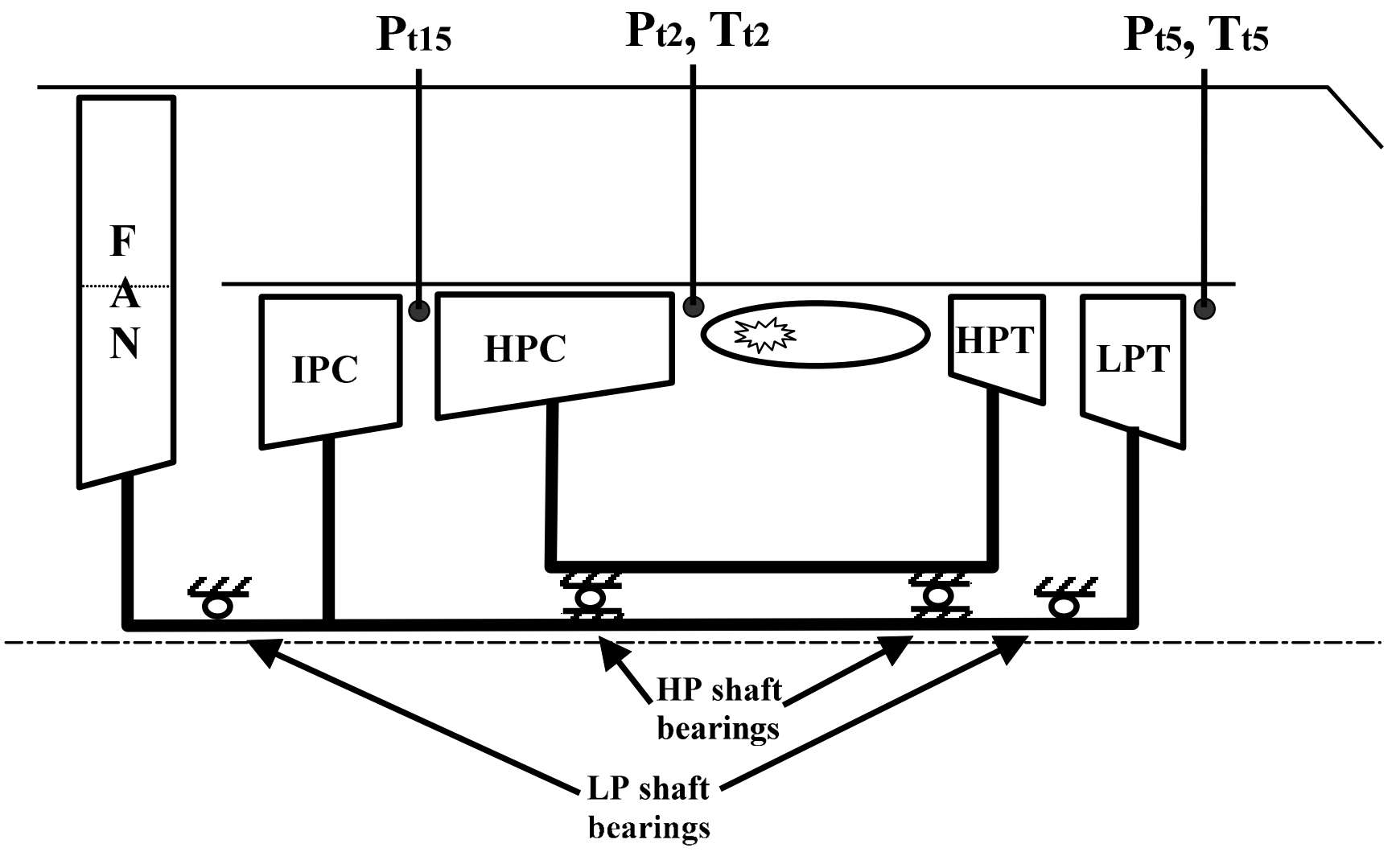

Figure 1. Model gas turbine turbofan engine

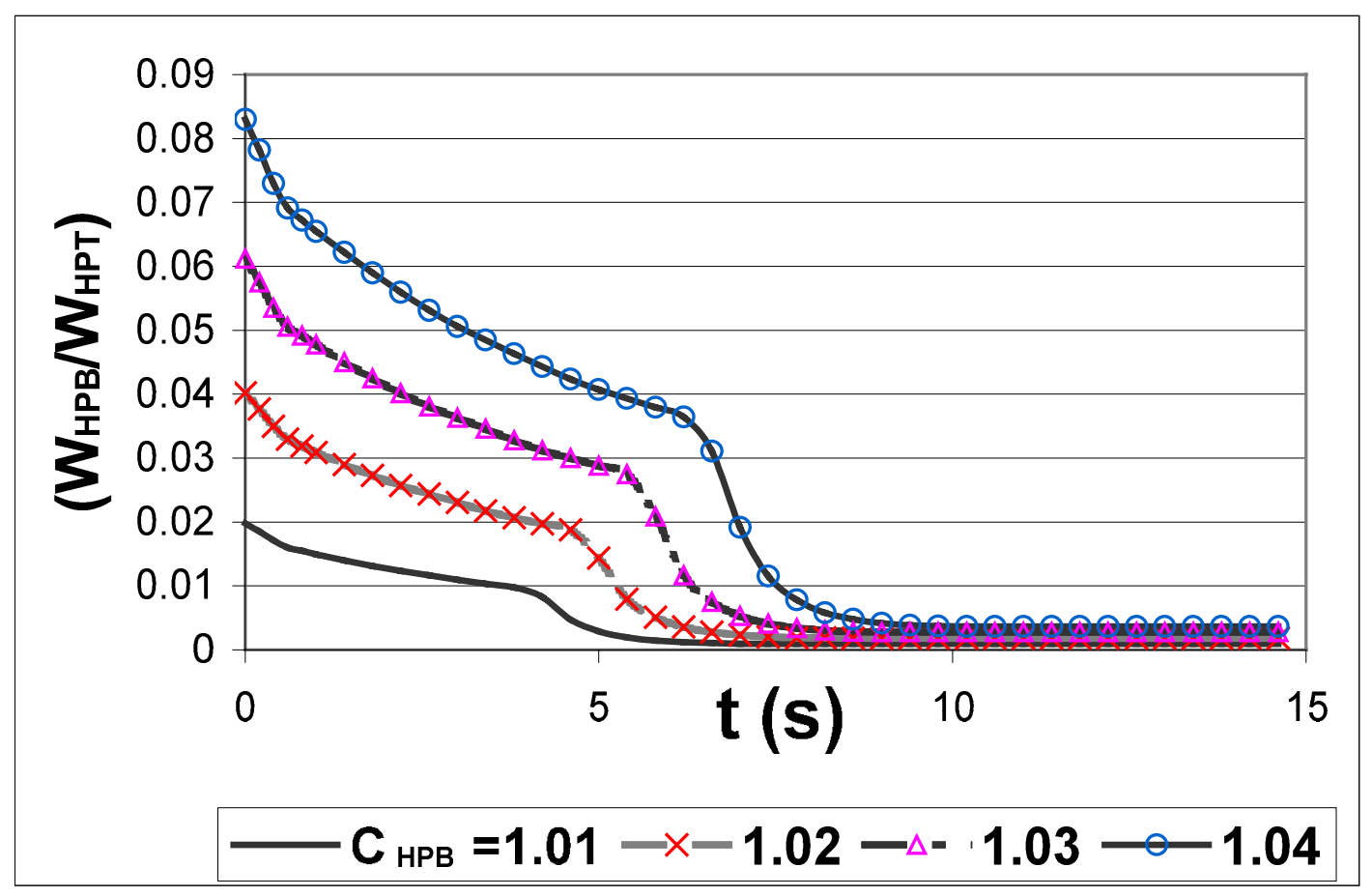

Figure 2. Variation of the ratio of HP shaft bearing loss and HP turbine power 


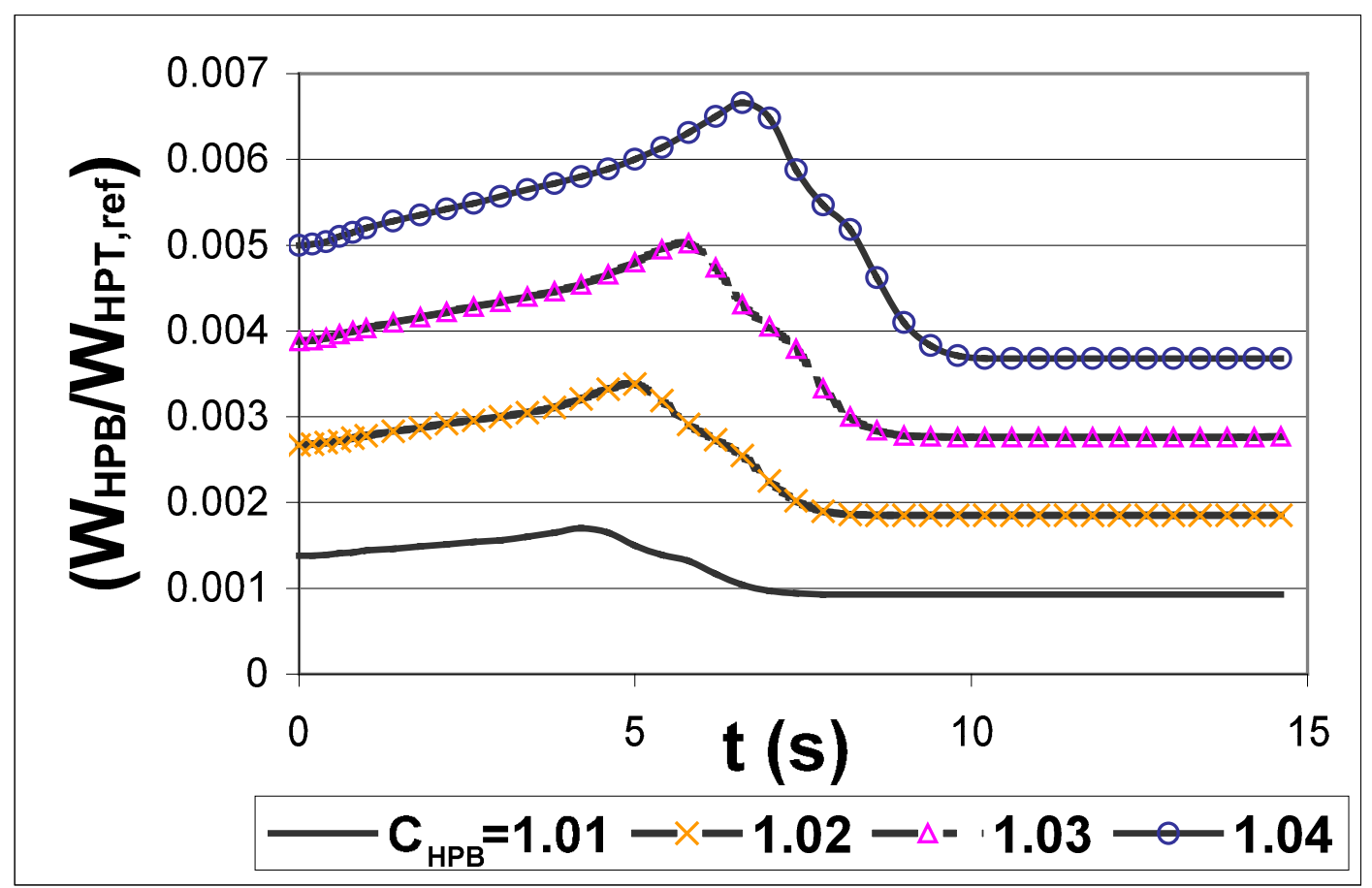

Figure 3. Variation of HP shaft bearing loss

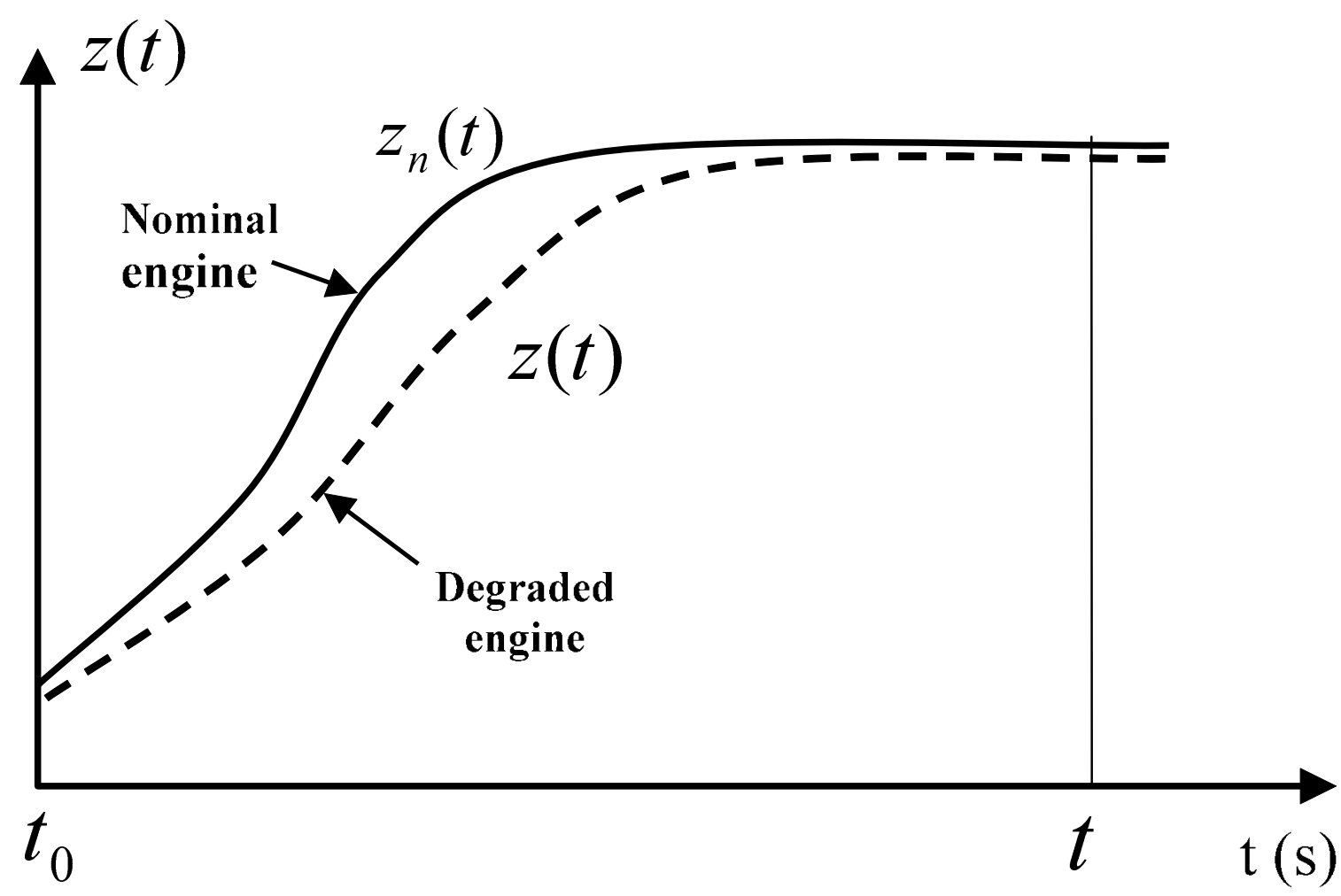

Figure 4. Trajectories of a nominal and degraded performance parameter 


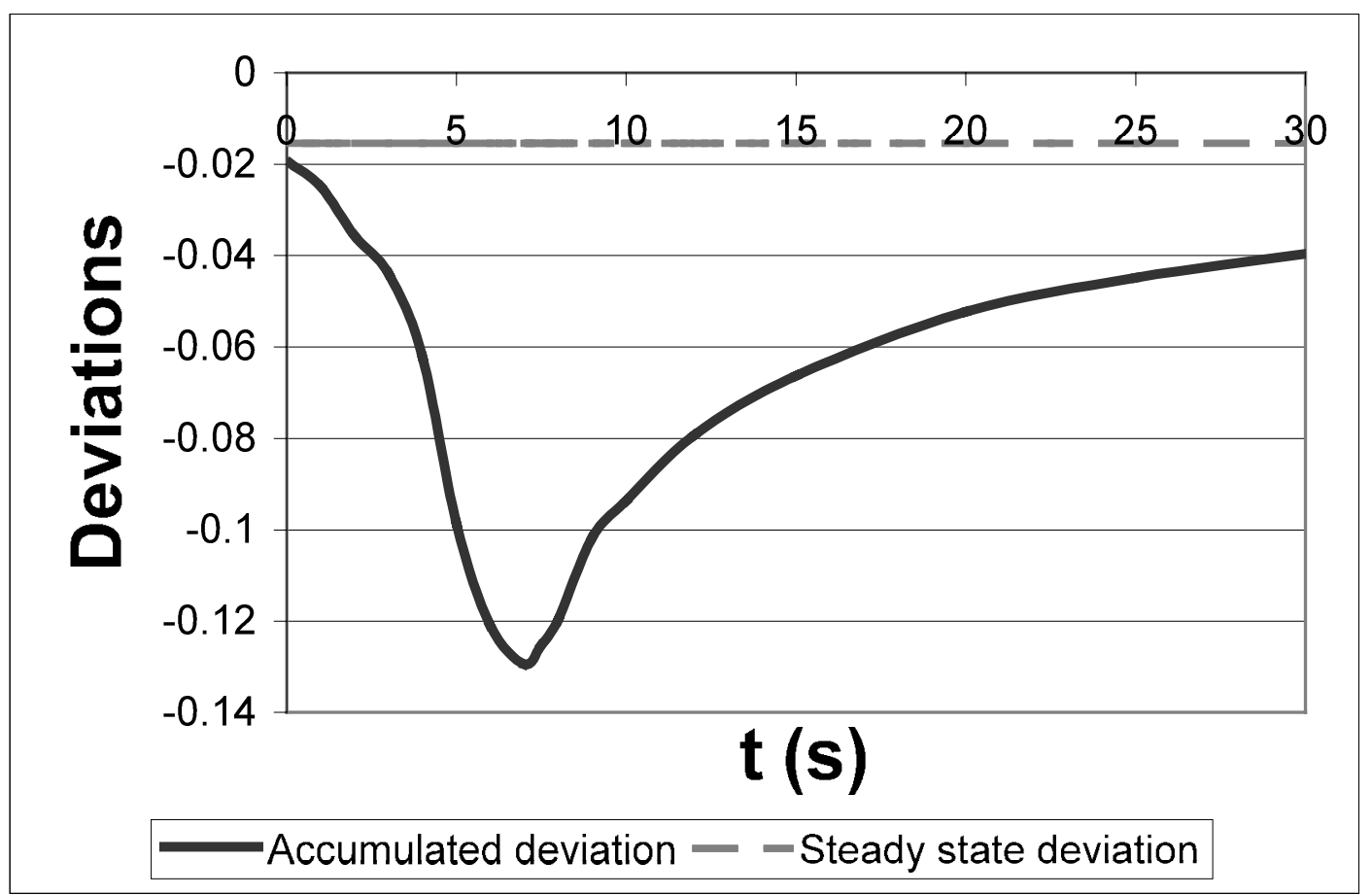

Figure 5. Accumulated deviation calculated with different integration time

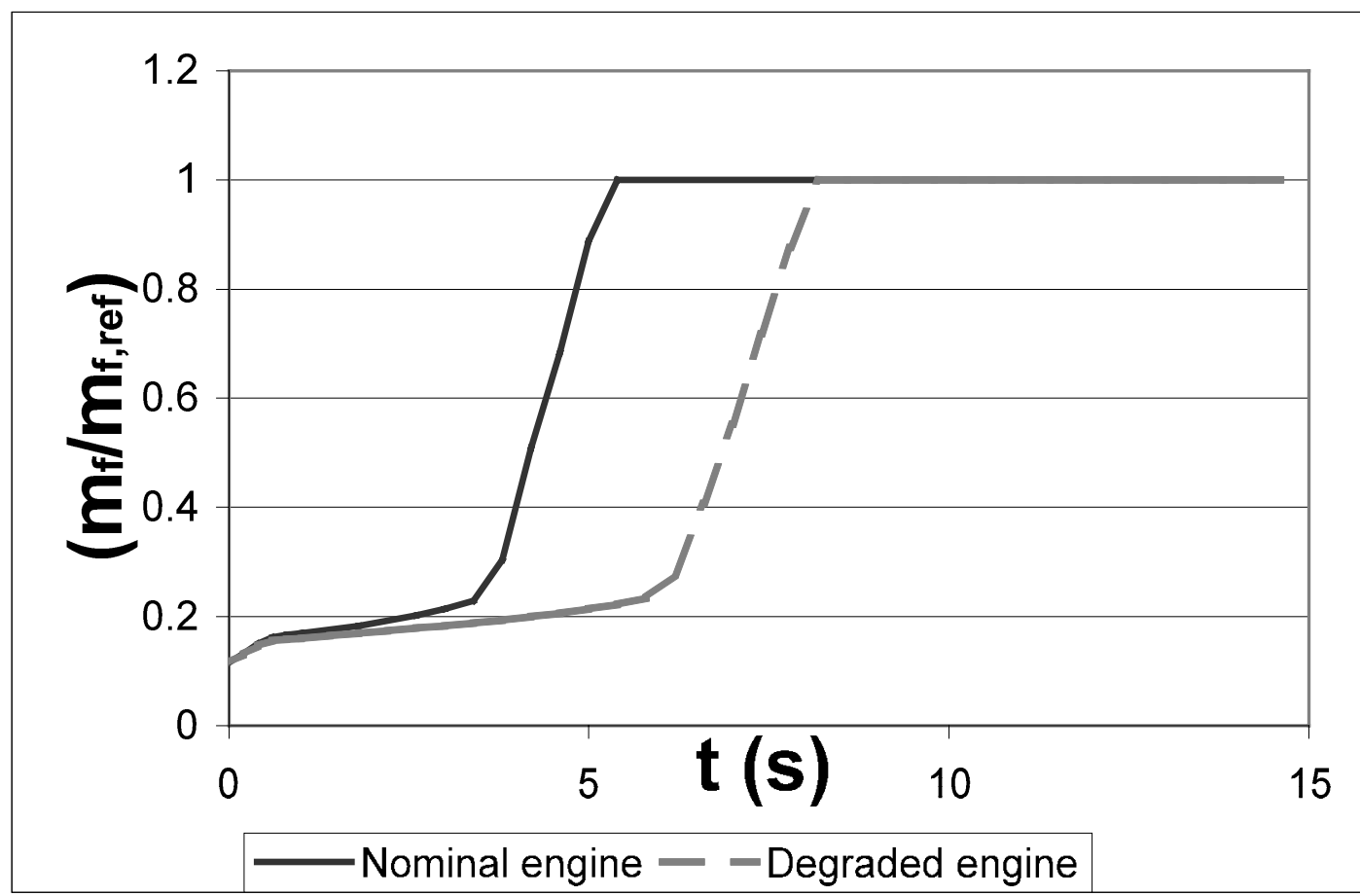

Figure 6. Fuel flow rate change due to HP turbine fault 


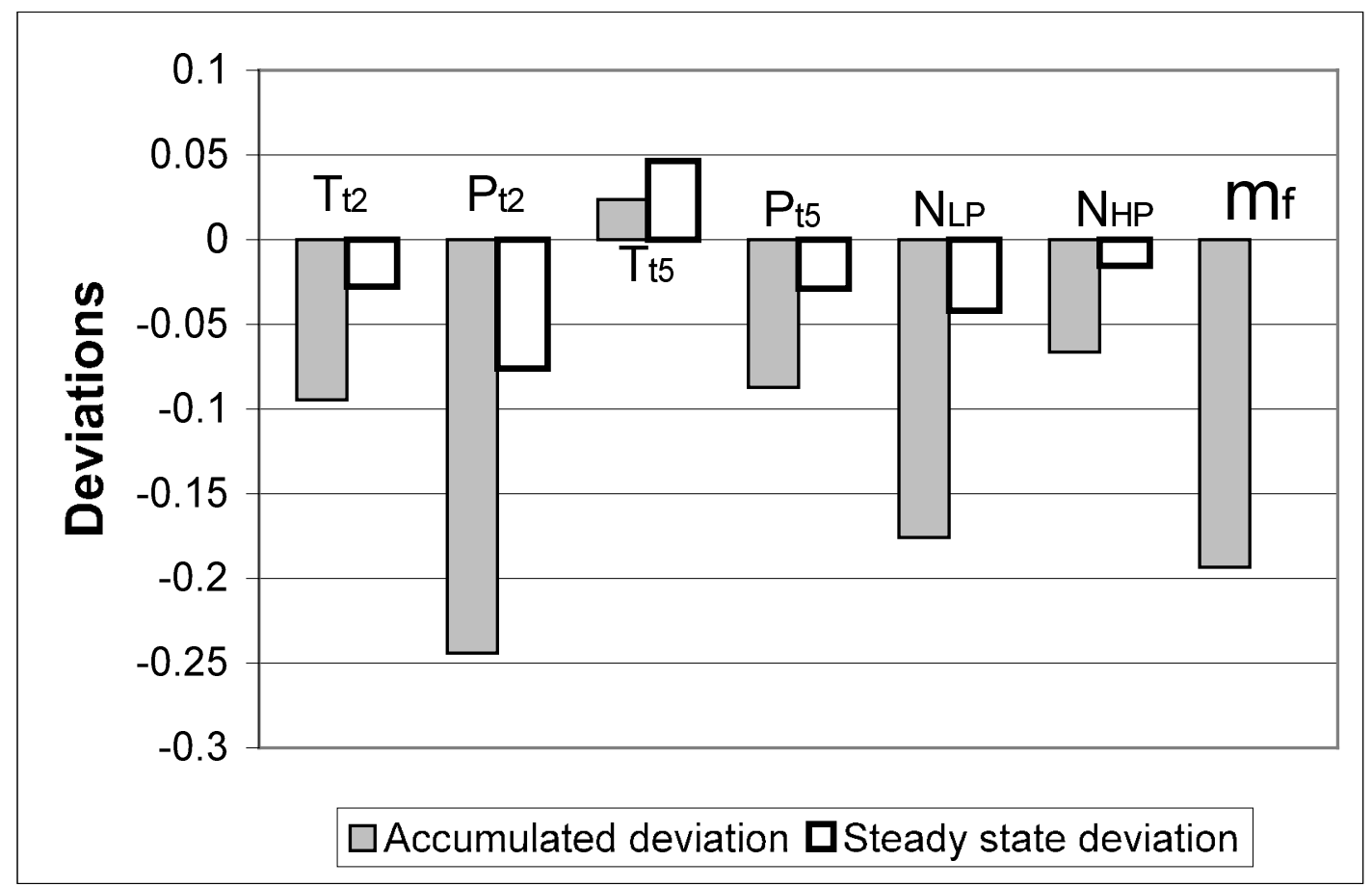

Figure 7. Fault signature of HP turbine fault ( $2 \%$ efficiency drop and $4 \%$ flow capacity rise)

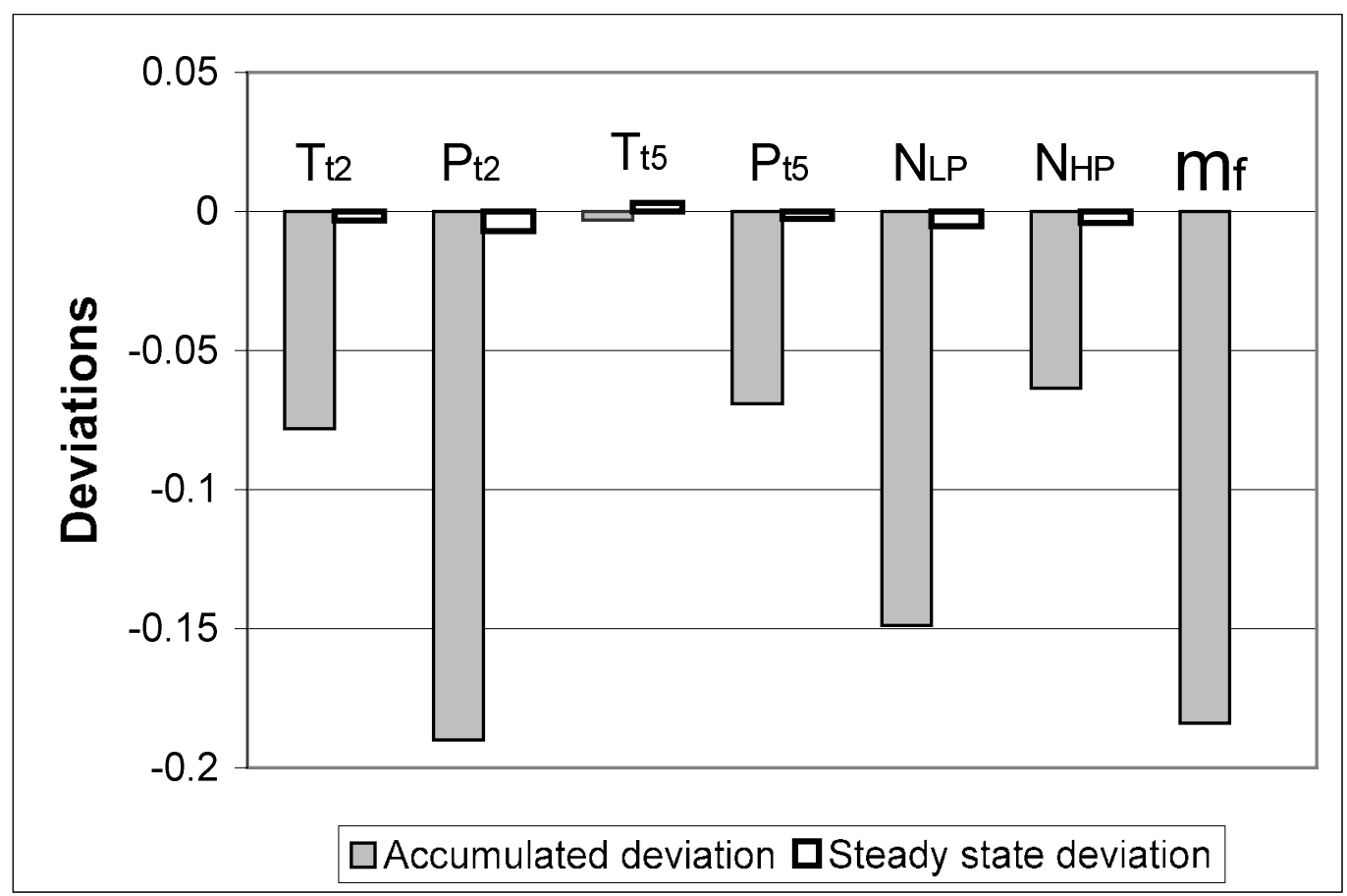

Figure 8. Fault signature of HP shaft bearing fault (1.04) 


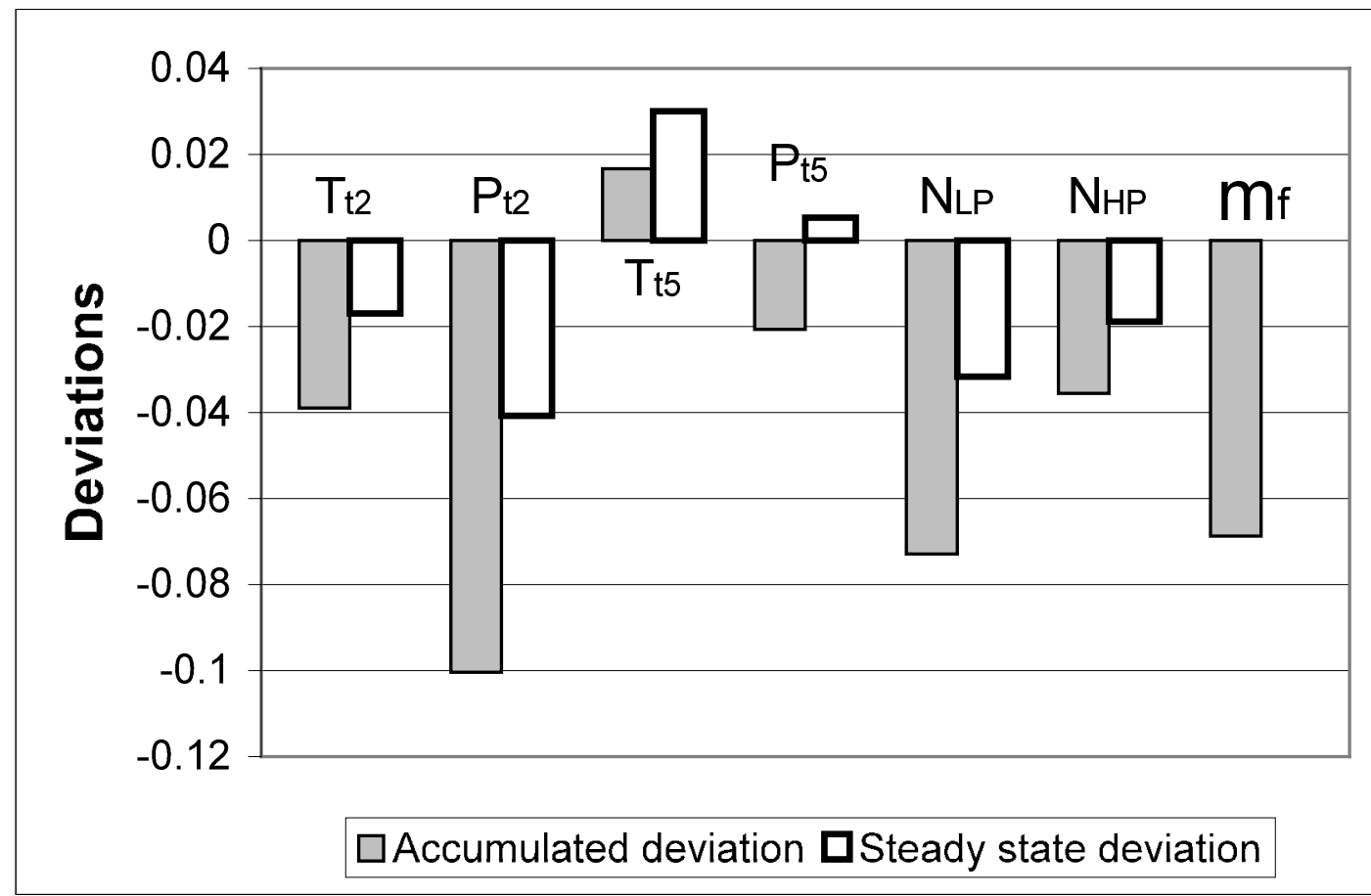

Figure 9. Fault signature of LP turbine fault ( $2 \%$ efficiency drop and $4 \%$ flow capacity drop)

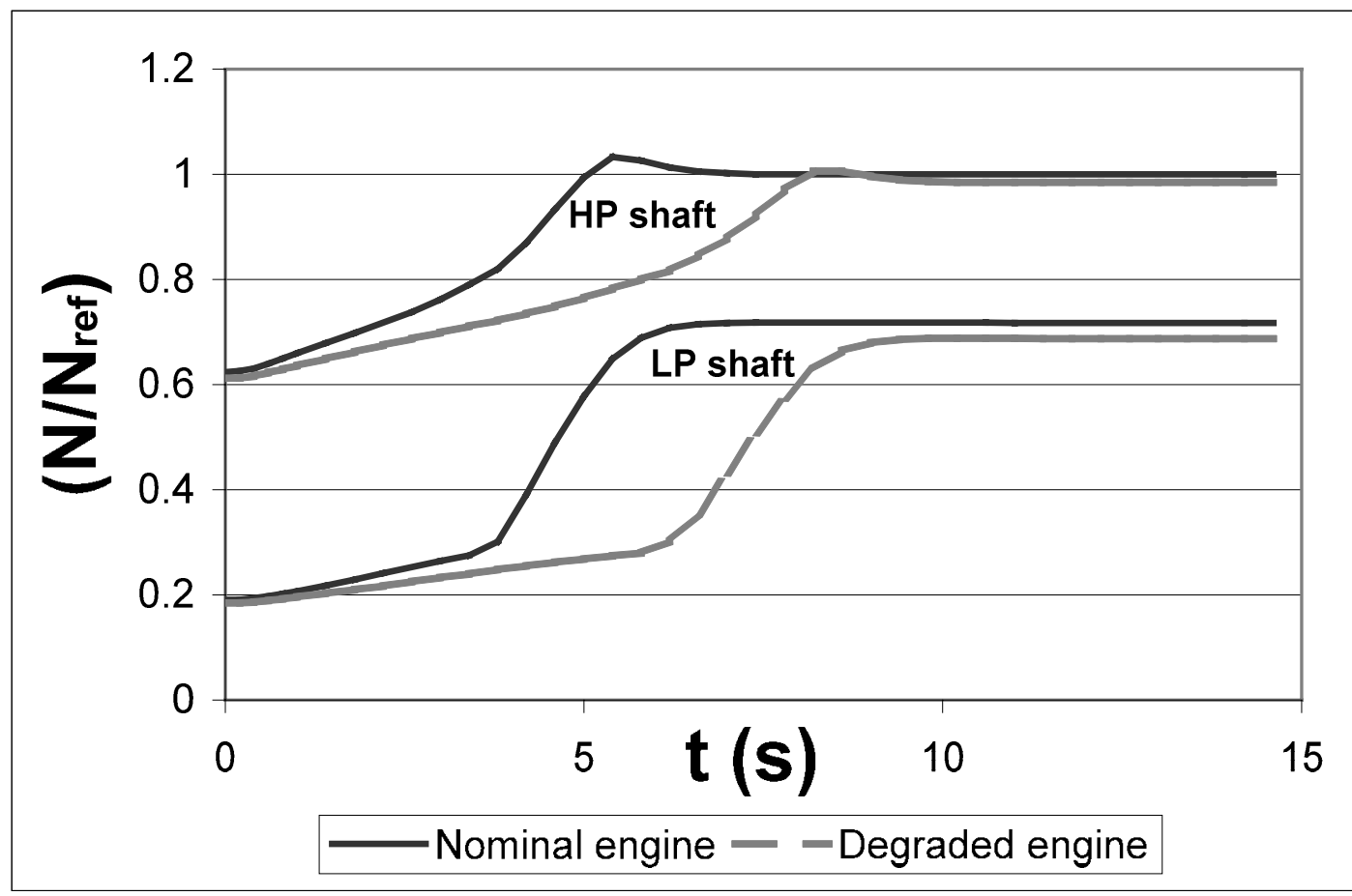

Figure 10. Shaft speed changes due to HP turbine fault 


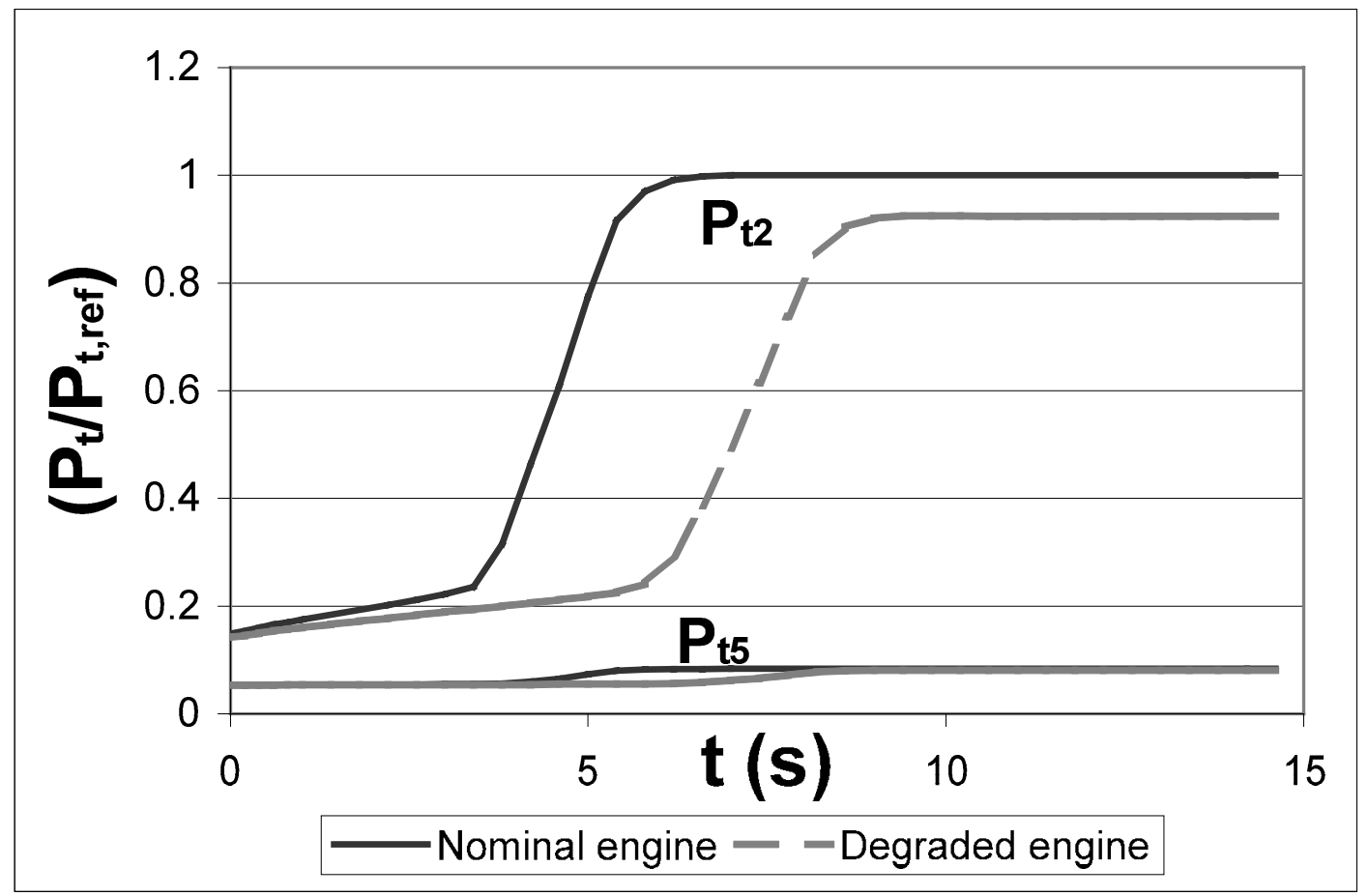

Figure 11. Total pressure changes due to HP turbine fault

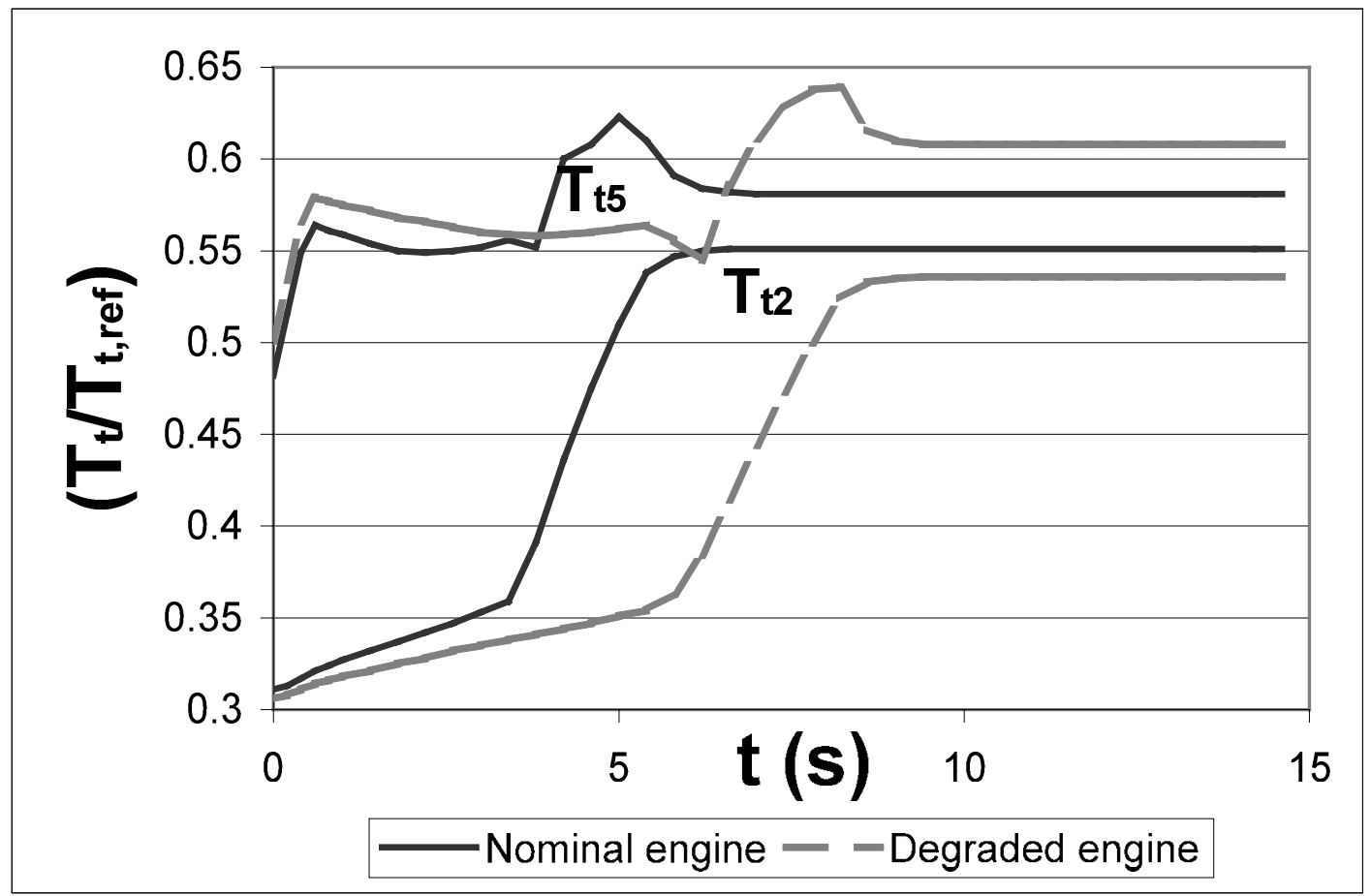

Figure 12. Total temperature changes due to HP turbine fault 


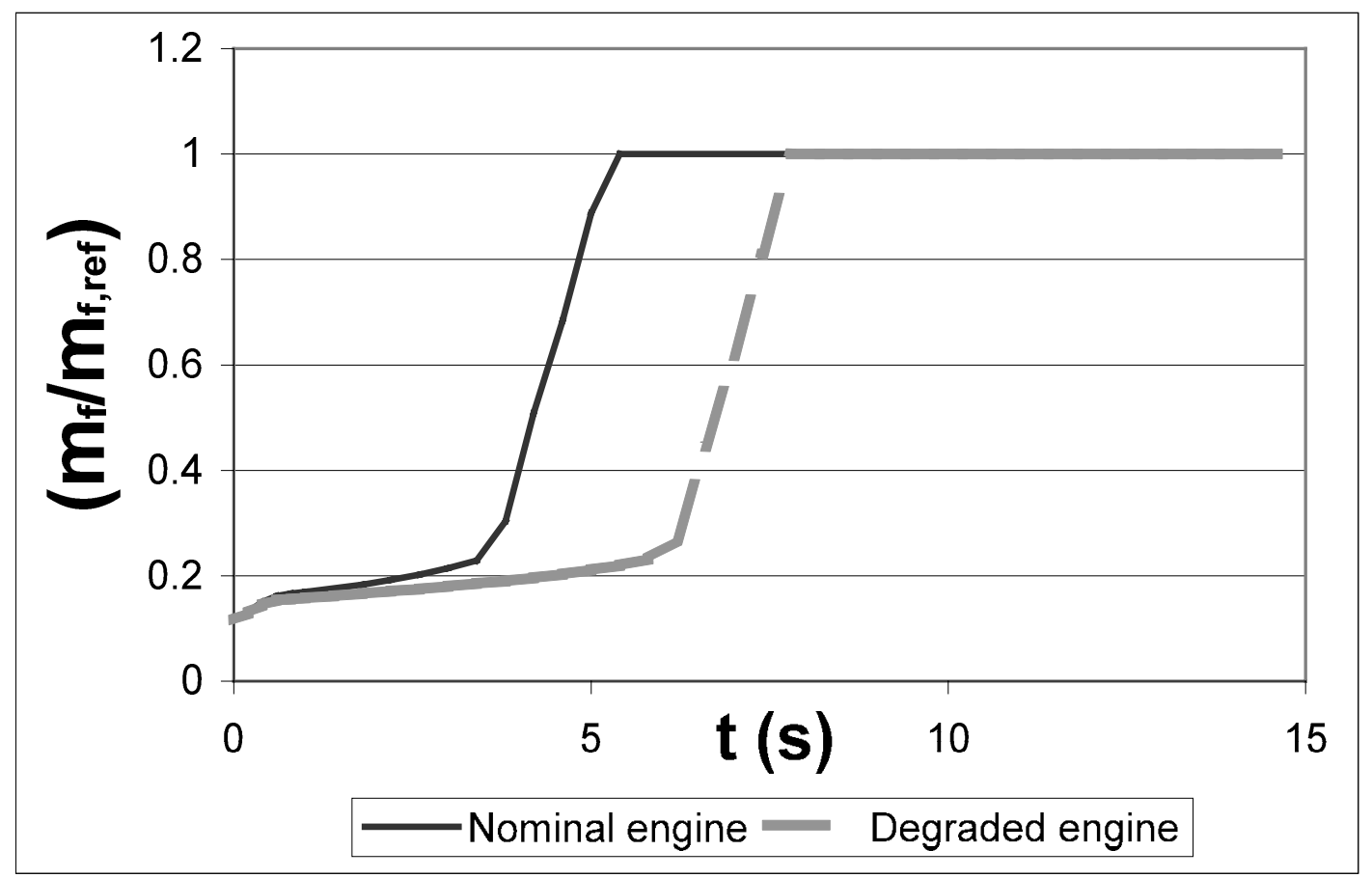

Figure 13. Fuel flow rate change due to HP shaft bearing failure

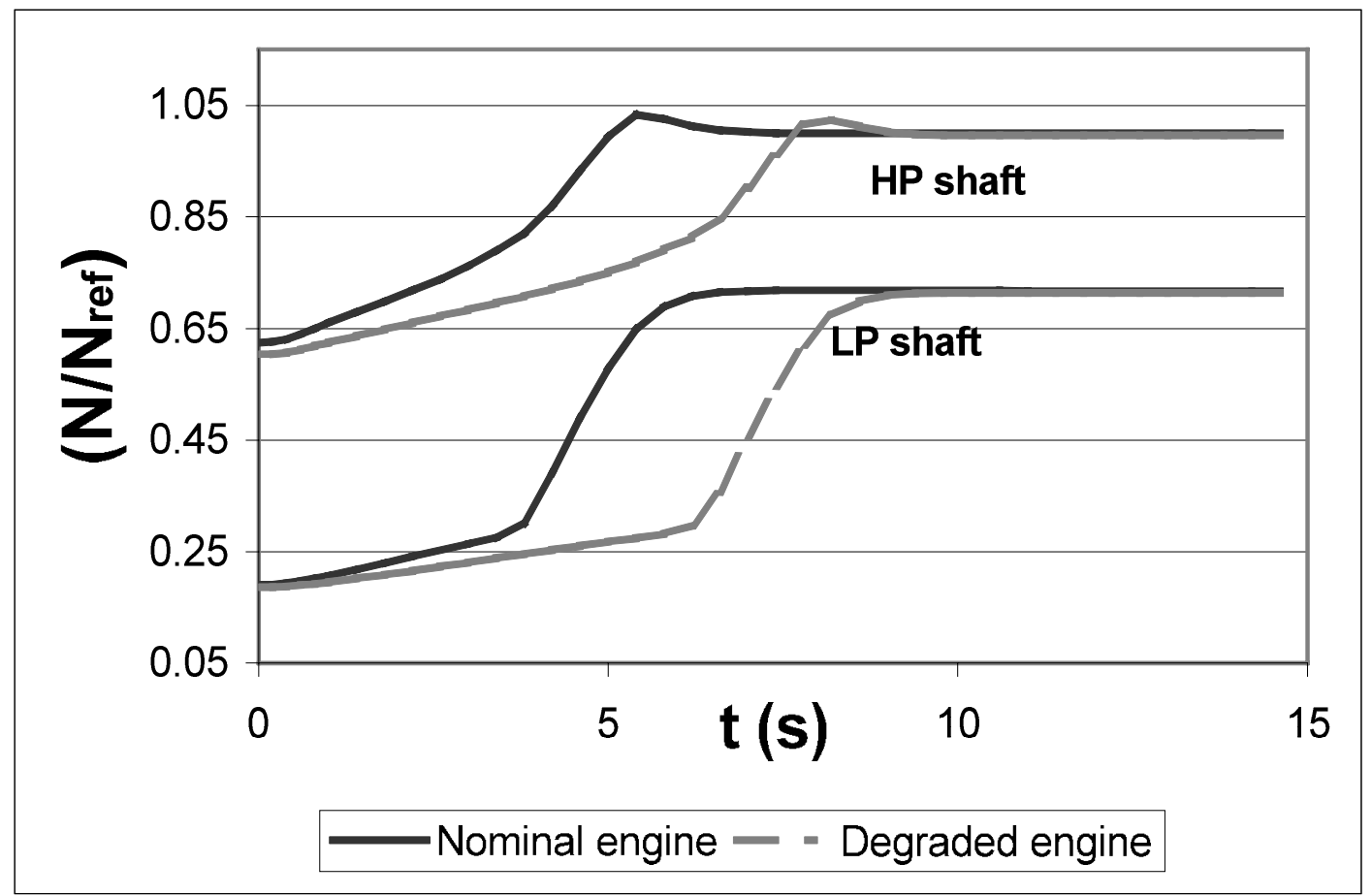

Figure 14. Shaft speed changes due to HP shaft bearing failure 


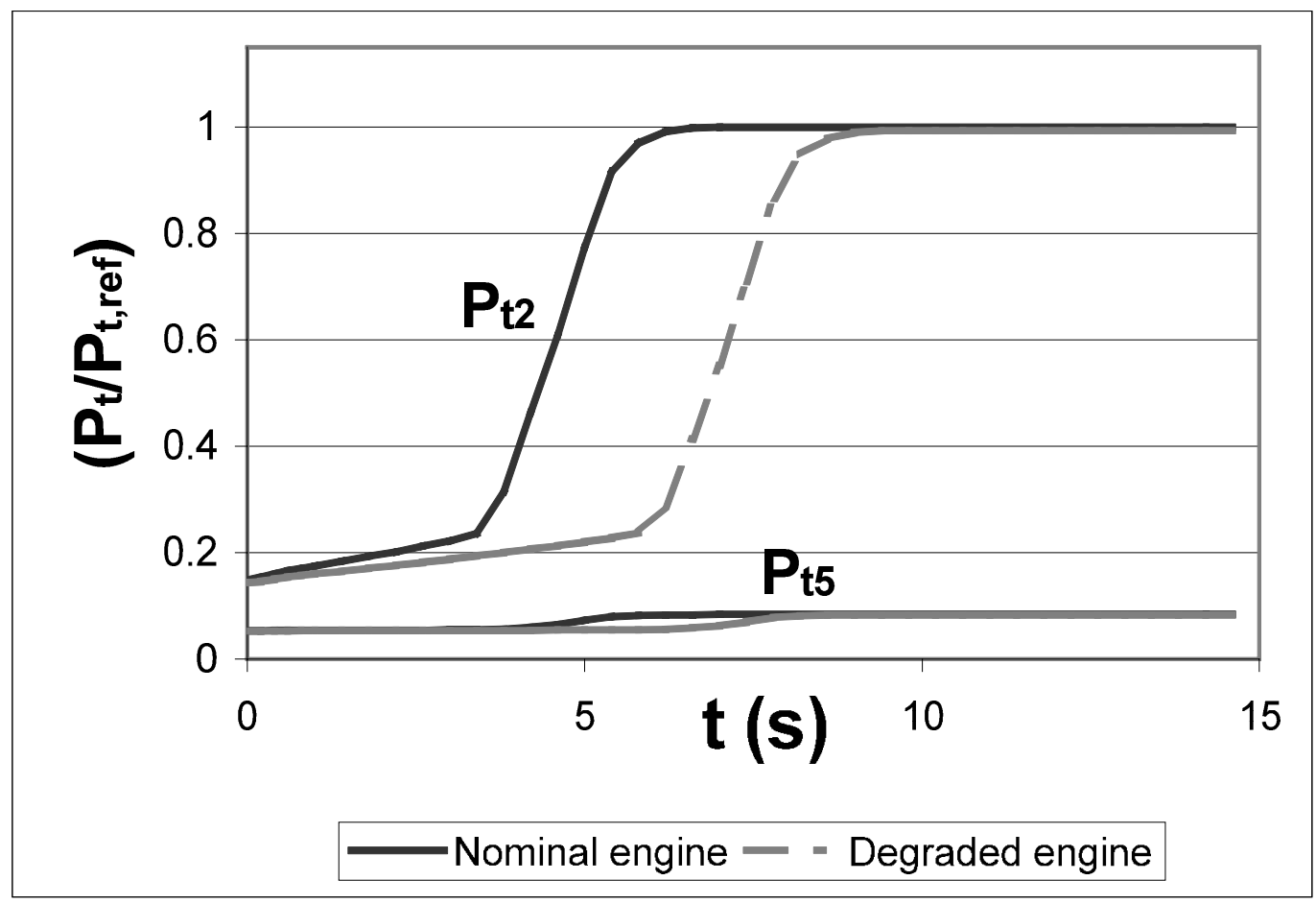

Figure 15. Total pressure changes due to HP shaft bearing failure

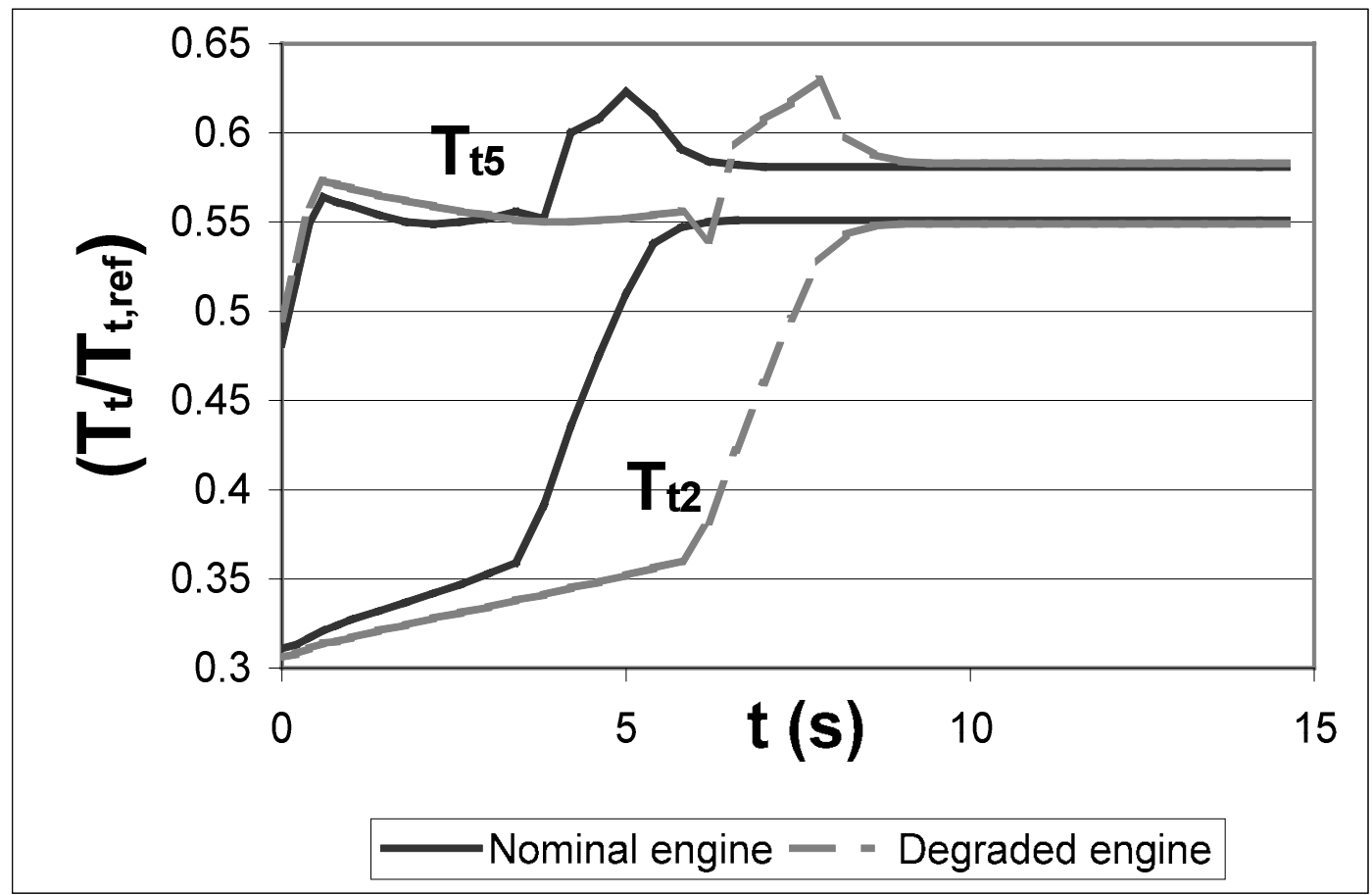

Figure 16. Total temperature changes due to HP shaft bearing failure 


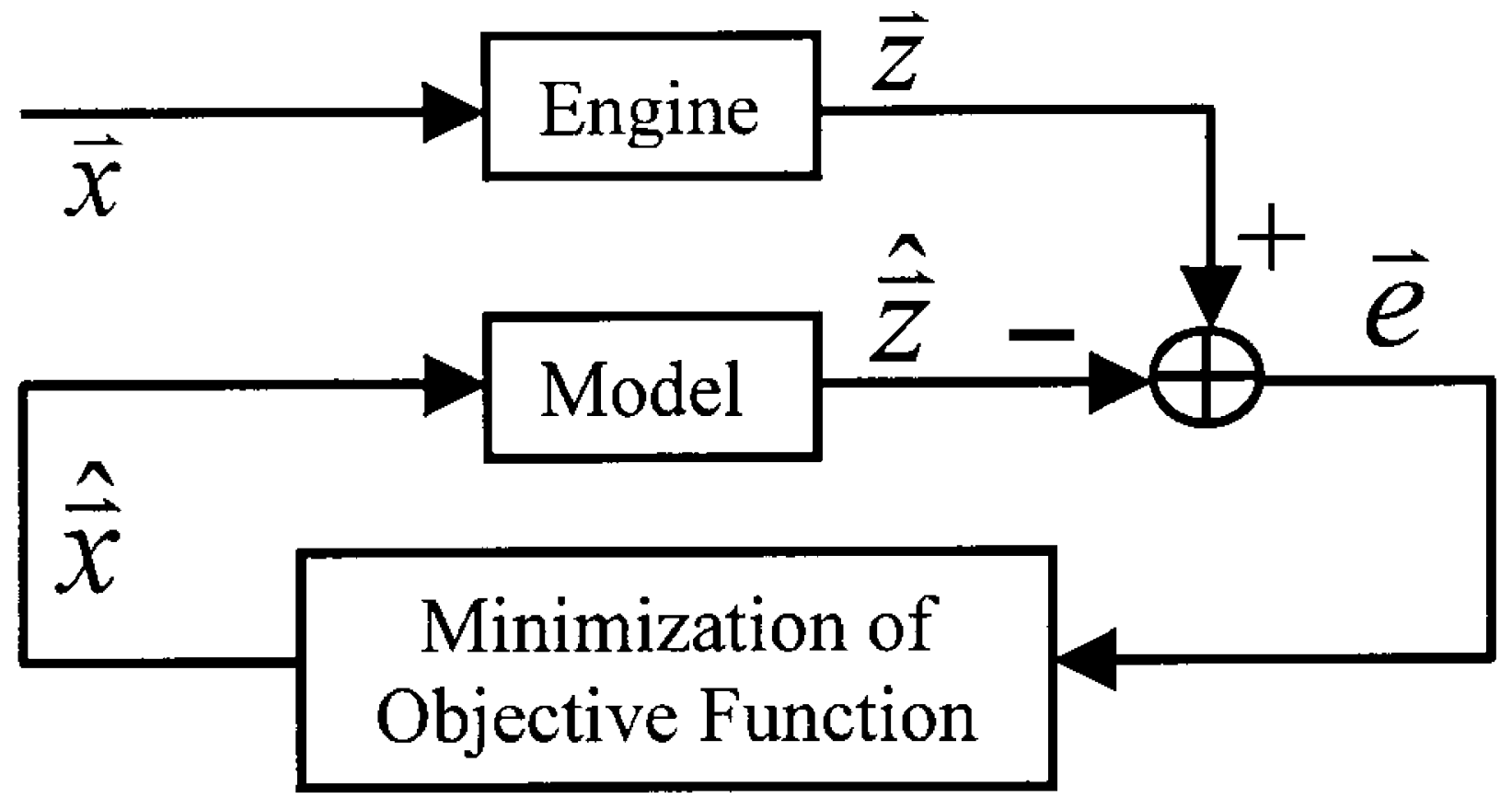

Figure 17. Non-linear model-based diagnostic model 